\title{
Low Levels of Serum Soluble Receptors for Advanced Glycation End Products, Biomarkers for Disease State: Myth or Reality
}

\author{
Kailash Prasad, MBBS (Hons), MD, PhD, FRCPC, FACC, FIACS, FICA ${ }^{1}$ \\ ${ }^{1}$ Department of Physiology, College of Medicine, University of \\ Saskatchewan, Saskatoon, Saskatchewan, Canada \\ Address for correspondence Kailash Prasad, MD, PhD, Department of \\ Physiology, College of Medicine, University of Saskatchewan, 107 \\ Wiggins Road, Saskatoon, Saskatchewan, Canada S7N 5E5 \\ Int J Angiol 2014;23:11-16. \\ (e-mail: k.prasad@usask.ca).
}

\begin{abstract}
Advanced glycation end products (AGEs) interact with the receptor for AGEs (RAGE) on the membrane and induce deleterious effects via activation of nuclear factor kappa-B, and increased oxidative stress and inflammatory mediators. AGEs also combine with circulating soluble receptors (endogenous secretory RAGE [esRAGE] and soluble receptor for RAGE [SRAGE]) and sequester RAGE ligands and act as a cytoprotective

\section{Keywords}

- advanced glycation end products

- soluble receptor for AGEs

- endogenous secretory receptor for AGEs

- biomarker

- coronary artery disease

- diabetes

- renal dysfunction

- unified biomarker for AGE-RAGE-associated diseases agent. esRAGE is secreted from the cells and is a spliced variant of RAGE. The sRAGE on the other hand is proteolytically cleaved from cell surface receptor via matrix metalloproteinase (MMPs). sRAGE is elevated in type 1 and type 2 diabetes and in patients with decreased renal function. Serum levels of sRAGE are reduced in diseases including coronary artery disease, atherosclerosis, essential hypertension, chronic obstructive lung disease, heart failure, and hypercholesterolemia. Serum levels of AGEs are elevated in patients with coronary artery disease and atherosclerosis. However, the increases in serum AGEs are very high in patients with diabetes and renal disease. There is a positive correlation between serum levels of AGEs and RAGE and sRAGE. The elevated levels of sRAGE in patients with diabetes and impaired renal function may be due to increased levels of MMPs. AGEs increase in the expression and production of MMPs, which would increase the cleavage of sRAGE from cell surface. In conclusion, low level of serum SRAGE is a good biomarker for disease other than diabetes and renal disease. A unified formula that takes into consideration of AGEs, sRAGE, and esRAGE such as AGE/sRAGE or AGEs/esRAGE would be better biomarker than sRAGE or esRAGE for all AGE-RAGEassociated diseases including diabetes and renal disease.
\end{abstract}

Low levels of soluble receptors for advanced glycation end products (SRAGE) have been suggested to be marker of disease states. However, the levels of sRAGE are elevated in some disease states. The contradictory findings have thrown shadow on the suggested use of low sRAGE as a marker for diseases. In this review, I am going to overview the status of the sRAGE as a marker of the disease processes. In doing so I am going to briefly describe the basics of AGEs and its cell surface receptor (RAGE) and circulating recep- tors (soluble receptor for AGEs [sRAGE] and endogenous secretory receptor [esRAGE]), the disease states where the levels of AGEs are elevated and the levels of SRAGE and esRAGE are decreased or elevated, and suggest why sRAGE or esRAGE are biomarker for disease states. A better solution for use of sRAGE and esRAGE in combination with AGEs as biomarkers of disease is provided. This will put to rest the controversy of use of sRAGE alone as a marker of disease. 


\section{AGEs-RAGE Axis}

AGEs are a heterogeneous group of irreversible abducts resulting from nonezymatic glycation and oxidation of proteins, nucleic acids, and lipids. ${ }^{1-3}$ AGEs formation proceeds slowly under euglycemic condition but is accelerated in hyperglycemia, oxidative stress, and conditions where protein and lipid turnovers are prolonged. ${ }^{4}$ There are four receptors for AGEs: full length RAGE, N-truncated RAGE, and C-truncated RAGE which has two isoforms, sRAGE and esRAGE. Full length RAGE is a multiligand member of immunoglobulin superfamily cell surface receptor. ${ }^{5}$ Its binding with various ligands results in alteration of several cell function through modulation of intracellular signaling, activation of nuclear-factor kappa-B, gene expression and release of inflammatory cytokines, and elevation of reactive oxygen species (ROS).$^{6-8}$ Interaction of AGEs and RAGE had adverse effects on cell function and initiates and helps in progression of the disease. N-truncated RAGE resides in the plasma membrane, but its function is poorly understood. C-truncated isoforms lack cytosolic and transmembrane domain and circulate in the blood. There are two isoforms of C-truncated RAGE: total soluble RAGE (sRAGE) and esRAGE. sRAGE is formed from the cleavage of the native membrane receptor mediated by disintegrins and MMPs. ${ }^{9}$ eSRAGE is formed from alternative splicing of native membrane receptor. ${ }^{10}$ Serum levels of sRAGE are five times higher than esRAGE in healthy subjects. ${ }^{10}$ Measurement of sRAGE includes esRAGE. Both sRAGE and esRAGE act as a decoy for RAGE ligands by sequestering RAGE ligands or competing with full RAGE for ligand binding ${ }^{11}$ and thus have cytoprotective effect against AGEs-RAGE interaction.

\section{Conditions Where sRAGE or esRAGE Levels Are Elevated}

Serum levels of sRAGE and esRAGE are elevated in type 2 diabetic patients with coronary artery disease or with atherosclerotic burden. ${ }^{12,13}$ Serum levels of sRAGE are high in type 2 diabetes compared with control. ${ }^{14}$ However, the serum levels of sRAGE have been reported low in type 2 diabetic patients compared with other controls. ${ }^{10}$ Challier et al ${ }^{15}$ reported that serum levels of sRAGE are higher in type 1 diabetes compared with nondiabetic control. Higher levels of sRAGE in type 1 diabetic patients are associated with incidental fatal and nonfatal cardiovascular disease. ${ }^{16}$ However, esRAGE levels are reduced in type 1 diabetes compared with nondiabetic controls. ${ }^{10,15,17}$ Elevated levels of sRAGE have been reported in patients with impaired renal function especially those with end-stage renal disease. ${ }^{18,19}$ Plasma levels of SRAGE are positively correlated with macro- and microvascular complications and renal dysfunction in type 1 diabetes. ${ }^{20}$ Elevated levels of sRAGE have been reported in patients with decreased renal function mainly with end-stage renal disease. ${ }^{21}$ These data suggest that serum sRAGE levels are elevated and esRAGE levels are reduced in both type 1 and type 2 diabetes patients. The serum levels of sRAGE are also elevated in patients with impaired renal function and endstage renal disease.

\section{Conditions Where sRAGE or esRAGE Levels Are Low}

Several investigators have reported that serum levels of SRAGE are lower in patients with coronary artery disease and atherosclerotic burden disease in nondiabetic men. ${ }^{22-27}$

Besides coronary artery disease and atherosclerosis, low levels of sRAGE have also been reported in hypercholesterolemia, ${ }^{28}$ essential hypertension, ${ }^{29}$ and Alzheimer disease and vascular dementia. ${ }^{30}$ sRAGE levels are significantly lower in patients with chronic obstructive pulmonary disease than in age- and sex-matched individual without airway obstruction. ${ }^{31,32}$ esRAGE levels of serum in patients with heart failure decreased in both diabetic and nondiabetic patients. ${ }^{33}$ These data suggest that both SRAGE and esRAGE are low in nondiabetic patients.

\section{Alteration in the Circulating Levels of AGEs in Disease State}

Serum levels of AGEs are elevated in patients with coronary artery disease. ${ }^{26,34,35}$ The levels of AGEs are 20 to $30 \%$ higher in people with uncomplicated type 1 diabetes ${ }^{36-38}$ and 40 to $100 \%$ higher in people with type 2 diabetes complicated with coronary artery disease or microalbuminuria. ${ }^{39,40}$ Kilhovd et $\mathrm{al}^{40}$ reported that serum levels of AGEs are increased in patients with type 2 diabetes compared with nondiabetic control subjects and that type 2 diabetic patients with coronary heart disease (CHD) had higher serum levels of AGEs compared with CHD patients without type 2 diabetes. The levels of serum AGEs are elevated in diabetic and nondiabetic subjects with coronary artery disease or renal dysfunction. ${ }^{41,42}$ The serum levels of AGEs in diabetic patients with hemodialysis are sixfold higher than those in patients with normoalbuminuria and microalbuminuria. ${ }^{43}$ The levels of serum AGEs are 5- to 100-fold higher in patients with end-stage renal disease compared with control subjects. ${ }^{44-46}$ These data suggest that circulating levels of AGEs are much higher in patients with diabetes and renal disease. Endogenous AGEs are determined by AGEs formation (hyperglycemia and oxidative stress) and renal excretion of AGEs. The formation and accumulation of AGEs progress at an accelerated rate in diabetes. It has been reported that the serum levels of AGEs in diabetic nephropathy is mainly due to decreased excretion by kidney rather than increased formation. ${ }^{43}$ Impairment of renal function reduces AGEs clearance in both diabetic and nondiabetic subjects. ${ }^{47}$

\section{Why sRAGE Is Reduced in Some Diseases and Elevated in Others While esRAGE Is Reduced in All Diseases?}

sRAGE and esRAGE counteract the effect of AGE and RAGE interaction by binding with AGEs. Both sRAGE and esRAGE neutralize the age-mediated damage by acting as a decoy. Low levels of sRAGE have been proposed as a biomarker of numerous disease states. ${ }^{21-32}$ However, in patients with 
diabetes, the sRAGE levels are elevated compared with control subjects. ${ }^{12-16}$ These data suggest that low serum levels of sRAGE may not be considered as a biomarker of all diseases. This raises questions as to why sRAGE levels in serum are elevated and esRAGE reduced in diabetic patients.

Patients with diabetes have higher levels of AGEs and sRAGE compared with controls, and levels of serum AGEs are positively correlated with serum sRAGE. AGEs upregulate RAGE expression in various tissue. ${ }^{48,49}$ There is a close correlation between serum levels of AGEs and endothelial RAGE expression. ${ }^{50}$ AGEs colocalize with RAGE, and AGEs-rich vasculature exhibits increased RAGE immunoreactivity. ${ }^{51,52}$ It is also known that there is a positive correlation between serum AGEs and sRAGE. ${ }^{14}$ esRAGE levels in the serum are correlated with AGEs in type 1 diabetes. ${ }^{53}$ The serum levels of sRAGE are positively correlated with the serum levels of AGEs in diabetic and nondiabetic patients. ${ }^{14}$ Also serum levels of sRAGE have been reported to correlate with the levels of AGEs in the vessel wall. ${ }^{54}$ Yamagishi et $\mathrm{al}^{55}$ have reported that serum levels of sRAGE are positively associated with serum levels of AGEs in nondiabetic general population and that the sRAGE levels are elevated in parallel with serum esRAGE. sRAGE levels are elevated in type 1 and type 2 diabetes $^{12-16}$ and in renal disease. ${ }^{19-21}$

The possibility exists that the elevated levels of sRAGE in diabetes and renal impairment may be due to a marked increase in the levels of serum AGEs which in turn would increase the expression of RAGE. Since both SRAGE and esRAGE are derived from RAGE, an alteration in the RAGE will be reflected in the alteration in SRAGE and esRAGE. Why then SRAGE is elevated while esRAGE is reduced in diabetes and renal disease? As mentioned earlier, esRAGE is a spliced variant of RAGE and SRAGE is a proteolytically cleaved form mediated by MMPs. ${ }^{9,56}$ The reason for elevated levels of SRAGE could be due to elevated levels of MMPs in diabetes and renal disease. Elevated levels of MMPs would increase the formation of sRAGE. High levels of AGEs in diabetes and renal disease as compared with other disease states would increase the expression of RAGE and hence increased formation of SRAGE. The question arises as to why MMPs will be elevated in diabetes and renal dysfunction?

In this context, it has been reported that AGEs induce expression and production of MMP-9 in marcrophages. ${ }^{57}$ Vascular MMP-9 activity is increased in diabetic patients. ${ }^{58}$ AGEs increases expression of MMP-1, -3, -9, and -13 in human osteoarthritic chondroyctes. ${ }^{59-61}$ Uemura et al ${ }^{62}$ reported an increase in vascular MMP-9 in diabetic patients. AGEs induce expression of MMP-2 and $-9 .{ }^{63-65}$ Expression of MMP-2 and -9 is upregulated in type 2 diabetes. ${ }^{66}$ Since levels of serum AGEs are markedly increased in patients with diabetes and end-stage renal disease, it is expected that the levels of MMPs would increase markedly in these conditions. There is another way of increasing expression of MMPs. Interaction of AGEs with RAGE increases production of ROS. ${ }^{4,7-9}$ ROS is known to increase the expression and activity of MMPs. ${ }^{67,68}$ The increases in expression and activity would increase levels of sRAGE in the serum. In spite of elevated levels of sRAGE, there is diabetic complication. This could be due to the fact that increase in the serum levels of sRAGE is not sufficient to remove the large amount of serum AGEs effectively.

\section{Suggested Biomarkers for Diseases Associated with AGE-RAGE Axis}

From the foregoing section, it appears that sRAGE and esRAGE levels in plasma are reduced or elevated in disease state. Reduced levels of serum sRAGE ${ }^{22-33}$ and esRAGE ${ }^{10,15,17,69}$ have been suggested to be biomarkers for diseases. However, it is known that SRAGE and esRAGE are elevated in other diseases. It appears that sRAGE or esRAGE by alone may not be a universal biomarker disease because their serum levels are elevated in some and reduced in others. AGE-RAGE axis involves four players: AGEs, cellular receptor RAGE, circulating receptors SRAGE, and esRAGE. In humans, it is not possible to measure cell receptor RAGE. However, AGEs, sRAGE, and esRAGE can be measured in serum. The other player besides SRAGE and esRAGE should be considered in the equation of universal biomarker for diseases associated with AGE-RAGE system. If only low SRAGE is considered as a disease biomarker, it cannot be applicable to diabetes and renal dysfunction because it is elevated in these diseases. Similarly, if only low serum esRAGE is considered as disease biomarker, then it will not be applicable for diseases where its levels are elevated. The serum levels of sRAGE and esRAGE have to be considered in conjunction with the serum levels of AGEs to identify a suitable universal biomarker for diseases. AGE is an important partner in the formulation of a universal biomarker. Complications occur in diabetes in spite of increased levels of sRAGE. This suggests that the elevation levels of serum AGEs are greater than elevation of sRAGE. Elevated levels of serum sRAGE are not sufficient to handle large amount of AGES effectively. It will be scientifically sound to use universal equation using both AGEs and circulating RAGE for disease biomarker. Unified formula for biomarker of disease should be AGES/sRAGE or AGEs/esRAGE. This formula will be better than SRAGE or esRAGE alone as a biomarker for diseases that are associated with AGE-RAGE axis. Since the serum levels of SRAGE are five times higher than esRAGE in healthy subjects, the AGEs/sRAGE may be better biomarker than AGEs/esRAGE.

\section{Acknowledgment}

The author acknowledges the financial assistance from the College of Medicine Research Fund, University of Saskatchewan, in the preparation of this manuscript.

\section{References}

1 Takeuchi M, Yanase Y, Matsuura N, et al. Immunological detection of a novel advanced glycation end-product. Mol Med 2001;7(11): 783-791

2 Thorpe SR, Baynes JW. Maillard reaction products in tissue proteins: new products and new perspectives. Amino Acids 2003; 25(3-4):275-281

3 Bierhaus A, Hofmann MA, Ziegler R, Nawroth PP. AGEs and their interaction with AGE-receptors in vascular disease and diabetes mellitus. I. The AGE concept. Cardiovasc Res 1998;37(3):586-600 
4 Prasad K. Soluble receptor for advanced glycation end products (sRAGE) and cardiovascular disease. Int J Angiol 2006;15:57-68

5 Neeper M, Schmidt AM, Brett J, et al. Cloning and expression of a cell surface receptor for advanced glycosylation end products of proteins. J Biol Chem 1992;267(21):14998-15004

6 Wendt T, Tanji N, Guo J, et al. Glucose, glycation, and RAGE: implications for amplification of cellular dysfunction in diabetic nephropathy. J Am Soc Nephrol 2003;14(5):1383-1395

7 Schmidt AM, Yan SD, Wautier JL, Stern D. Activation of receptor for advanced glycation end products: a mechanism for chronic vascular dysfunction in diabetic vasculopathy and atherosclerosis. Circ Res 1999;84(5):489-497

8 Schmidt AM, Yan SD, Yan SF, Stern DM. The biology of the receptor for advanced glycation end products and its ligands. Biochim Biophys Acta 2000;1498(2-3):99-111

9 Tam XHL, Shiu SWM, Leng L, Bucala R, Betteridge DJ, Tan KCB. Enhanced expression of receptor for advanced glycation endproducts is associated with low circulating soluble isoforms of the receptor in Type 2 diabetes. Clin Sci (Lond) 2011;120(2):81-89

10 Koyama H, Shoji T, Yokoyama H, et al. Plasma level of endogenous secretory RAGE is associated with components of the metabolic syndrome and atherosclerosis. Arterioscler Thromb Vasc Biol 2005;25(12):2587-2593

11 Geroldi D, Falcone C, Emanuele E. Soluble receptor for advanced glycation end products: from disease marker to potential therapeutic target. Curr Med Chem 2006;13(17):1971-1978

12 Colhoun HM, Betteridge DJ, Durrington P, et al. Total soluble and endogenous secretory receptor for advanced glycation end products as predictive biomarkers of coronary heart disease risk in patients with type 2 diabetes: an analysis from the CARDS trial. Diabetes 2011;60(9):2379-2385

13 Fujisawa K, Katakami N, Kaneto H, et al. Circulating soluble RAGE as a predictive biomarker of cardiovascular event risk in patients with type 2 diabetes. Atherosclerosis 2013;227(2):425-428

14 Tan KCB, Shiu SWM, Chow WS, Leng L, Bucala R, Betteridge DJ. Association between serum levels of soluble receptor for advanced glycation end products and circulating advanced glycation end products in type 2 diabetes. Diabetologia 2006;49(11):2756-2762

15 Challier M, Jacqueminet S, Benabdesselam O, Grimaldi A, Beaudeux JL. Increased serum concentrations of soluble receptor for advanced glycation endproducts in patients with type 1 diabetes. Clin Chem 2005;51(9):1749-1750

16 Nin JW, Jorsal A, Ferreira I, et al. Higher plasma soluble Receptor for Advanced Glycation End Products (sRAGE) levels are associated with incident cardiovascular disease and all-cause mortality in type 1 diabetes: a 12-year follow-up study. Diabetes 2010;59(8): 2027-2032

17 Katakami N, Matsuhisa M, Kaneto H, et al. Decreased endogenous secretory advanced glycation end product receptor in type 1 diabetic patients: its possible association with diabetic vascular complications. Diabetes Care 2005;28(11):2716-2721

18 Kalousová M, Hodková M, Kazderová M, et al. Soluble receptor for advanced glycation end products in patients with decreased renal function. Am J Kidney Dis 2006;47(3):406-411

19 Basta G, Leonardis D, Mallamaci F, et al. Circulating soluble receptor of advanced glycation end product inversely correlates with atherosclerosis in patients with chronic kidney disease. Kidney Int 2010;77(3):225-231

20 Nin JWM, Ferreira I, Schalkwijk CG, et al; EURODIAB Prospective Complications Study Group. Levels of soluble receptor for AGE are cross-sectionally associated with cardiovascular disease in type 1 diabetes, and this association is partially mediated by endothelial and renal dysfunction and by low-grade inflammation: the EURODIAB Prospective Complications Study. Diabetologia 2009;52(4): 705-714

21 Hammady MMR, Khashali SEL, Halim HA, Rashed L, Hussein M. Soluble receptor for advanced glycation end products (sRAGE) in non-diabetic hemodialysis patients and chronic kidney disease. Med J Cairo Univ 2012;80:69-75

22 Falcone C, Emanuele E, D’Angelo A, et al. Plasma levels of soluble receptor for advanced glycation end products and coronary artery disease in nondiabetic men. Arterioscler Thromb Vasc Biol 2005; 25(5):1032-1037

23 Lindsey JB, de Lemos JA, Cipollone F, et al. Association between circulating soluble receptor for advanced glycation end products and atherosclerosis: observations from the Dallas Heart Study. Diabetes Care 2009;32(7):1218-1220

24 Hudson BI, Moon YP, Kalea AZ, et al. Association of serum soluble receptor for advanced glycation end-products with subclinical cerebrovascular disease: the Northern Manhattan Study (NOMAS). Atherosclerosis 2011;216(1):192-198

25 Selvin EM, Halushka MK, Rawlings AM, et al. sRAGE and risk of diabetes, cardiovascular disease, and death. Diabetes 2013;62(6): 2116-2121

26 McNair ED, Wells CR, Qureshi AM, et al. Low levels of soluble receptor for advanced glycation end products in non-ST elevation myocardial infarction patients. Int J Angiol 2009;18(4):187-192

27 McNair ED, Wells CR, Mabood Qureshi A, et al. Soluble receptors for advanced glycation end products (sRAGE) as a predictor of restenosis following percutaneous coronary intervention. Clin Cardiol 2010;33(11):678-685

28 Santilli F, Bucciarelli L, Noto D, et al. Decreased plasma soluble RAGE in patients with hypercholesterolemia: effects of statins. Free Radic Biol Med 2007;43(9):1255-1262

29 Geroldi D, Falcone C, Emanuele E, et al. Decreased plasma levels of soluble receptor for advanced glycation end-products in patients with essential hypertension. J Hypertens 2005;23(9):1725-1729

30 Emanuele E, D'Angelo A, Tomaino C, et al. Circulating levels of soluble receptor for advanced glycation end products in Alzheimer disease and vascular dementia. Arch Neurol 2005;62(11): 1734-1736

31 Miniati M, Monti S, Basta G, Cocci F, Fornai E, Bottai M. Soluble receptor for advanced glycation end products in COPD: relationship with emphysema and chronic cor pulmonale: a case-control study. Respir Res 2011;12:37-45

32 Smith DJ, Yerkovich ST, Towers MA, Carroll ML, Thomas R, Upham JW. Reduced soluble receptor for advanced glycation end-products in COPD. Eur Respir J 2011;37(3):516-522

33 Wang LJ, Lu L, Zhang FR, Chen QJ, De Caterina R, Shen WF. Increased serum high-mobility group box-1 and cleaved receptor for advanced glycation endproducts levels and decreased endogenous secretory receptor for advanced glycation endproducts levels in diabetic and non-diabetic patients with heart failure. Eur J Heart Fail 2011;13(4):440-449

34 Basta G, Berti S, Cocci F, et al. Plasma N-epsilon-(carboxymethyl) lysine levels are associated with the extent of vessel injury after coronary arterial stenting. Coron Artery Dis 2008;19(5):299-305

35 Taki K, Takayama F, Tsuruta Y, Niwa T. Oxidative stress, advanced glycation end product, and coronary artery calcification in hemodialysis patients. Kidney Int 2006;70(1):218-224

36 Tan KCB, Chow WS, Tam S, Bucala R, Betteridge J. Association between acute-phase reactants and advanced glycation end products in type 2 diabetes. Diabetes Care 2004;27(1):223-228

37 Berg TJ, Dahl-Jørgensen K, Torjesen PA, Hanssen KF. Increased serum levels of advanced glycation end products (AGEs) in children and adolescents with IDDM. Diabetes Care 1997;20(6): 1006-1008

38 Berg TJ, Clausen JT, Torjesen PA, Dahl-Jørgensen K, Bangstad HJ, Hanssen KF. The advanced glycation end product Nepsilon-(carboxymethyl)lysine is increased in serum from children and adolescents with type 1 diabetes. Diabetes Care 1998;21(11):1997-2002

39 Sharp PS, Rainbow S, Mukherjee S. Serum levels of low molecular weight advanced glycation end products in diabetic subjects. Diabet Med 2003;20(7):575-579 
40 Kilhovd BK, Berg TJ, Birkeland KI, Thorsby P, Hanssen KF. Serum levels of advanced glycation end products are increased in patients with type 2 diabetes and coronary heart disease. Diabetes Care 1999;22(9):1543-1548

41 Kanauchi M, Tsujimoto N, Hashimoto T. Advanced glycation end products in nondiabetic patients with coronary artery disease. Diabetes Care 2001;24(9):1620-1623

42 Selvaraj N, Bobby Z, Das AK, Ramesh R, Koner BC. An evaluation of level of oxidative stress and protein glycation in nondiabetic undialyzed chronic renal failure patients. Clin Chim Acta 2002; 324(1-2):45-50

43 Shimoike T, Inoguchi T, Umeda F, Nawata H, Kawano K, Ochi H. The meaning of serum levels of advanced glycosylation end products in diabetic nephropathy. Metabolism 2000;49(8):1030-1035

44 Raj DS, Choudhury D, Welbourne TC, Levi M. Advanced glycation end products: a Nephrologist's perspective. Am J Kidney Dis 2000; 35(3):365-380

45 Papanastasiou P, Grass L, Rodela H, Patrikarea A, Oreopoulos D, Diamandis EP. Immunological quantification of advanced glycosylation end-products in the serum of patients on hemodialysis or CAPD. Kidney Int 1994;46(1):216-222

46 Makita Z, Radoff S, Rayfield EJ, et al. Advanced glycosylation end products in patients with diabetic nephropathy. N Engl J Med 1991;325(12):836-842

47 Miyata T, van Ypersele de Strihou C, Kurokawa K, Baynes JW. Alterations in nonenzymatic biochemistry in uremia: origin and significance of "carbonyl stress" in long-term uremic complications. Kidney Int 1999;55(2):389-399

48 Schmidt AM, Stern D. Atherosclerosis and diabetes: the RAGE connection. Curr Atheroscler Rep 2000;2(5):430-436

49 Beirhaus A, Schiekofer S, Schwaninger M, et al. P. Diabetes-associated sustained activation of the transcription factor nuclear factorkappaB. Diabetes 2001;50(2):2792-2808

50 Zhang WR, Hou FF, Liu SX, et al. Advanced glycation end products accelerate atherosclerosis via enhancement of oxidative stress [in Chinese]. Zhonghua Yi Xue Za Zhi 2004;84(13):1066-1072

51 Ritthaler U, Deng Y, Zhang Y, et al. Expression of receptors for advanced glycation end products in peripheral occlusive vascular disease. Am J Pathol 1995;146(3):688-694

52 Soulis T, Thallas V, Youssef $\mathrm{S}$, et al. Advanced glycation end products and their receptors co-localise in rat organs susceptible to diabetic microvascular injury. Diabetologia 1997;40(6): 619-628

53 Miura J, Yamamoto Y, Osawa M, et al. Endogenous secretory receptor for advanced glycation endproducts levels are correlated with serum pentosidine and CML in patients with type 1 diabetes. Arterioscler Thromb Vasc Biol 2007;27(1):253-254

54 Stitt AW, He C, Friedman S, et al. Elevated AGE-modified ApoB in sera of euglycemic, normolipidemic patients with atherosclerosis: relationship to tissue AGEs. Mol Med 1997;3(9):617-627

55 Yamagishi S, Adachi H, Nakamura K, et al. Positive association between serum levels of advanced glycation end products and the soluble form of receptor for advanced glycation end products in nondiabetic subjects. Metabolism 2006;55(9):1227-1231

56 Yonekura H, Yamamoto Y, Sakurai S, et al. Novel splice variants of the receptor for advanced glycation end-products expressed in human vascular endothelial cells and pericytes, and their putative roles in diabetes-induced vascular injury. Biochem J 2003;370(Pt 3):1097-1109

57 Zhang F, Kent KC, Yamanouchi D, et al. Anti-receptor for advanced glycation end products therapies as novel treatment for abdominal aortic aneurysm. Ann Surg 2009;250(3):416-423

58 Zhang F, Banker G, Liu X, et al. The novel function of advanced glycation end products in regulation of MMP-9 production. J Surg Res 2011;171(2):871-876

59 Rasheed Z, Anbazhagan AN, Akhtar N, Ramamurthy S, Voss FR, Haqqi TM. Green tea polyphenol epigallocatechin-3-gallate inhibits advanced glycation end products- induced expression of tumor necrosis factor-alpha and matrix metalloproteinase-13 in human chondrocytes. Arthritis Res Ther 2009;11:R71

60 Nah SS, Choi IY, Yoo B, Kim YG, Moon HB, Lee CK. Advanced glycation end products increases matrix metalloproteinase- $1,-3$, and -13 , and TNF- $\alpha$ in human osteoarthritic chondrocytes. FEBS Lett 2007;581(9):1928-1932

61 Dai R, Wang L, Jim H, Sun Z. Effects of advanced glycation end products on expression of EMMPRIN and MMP-2 in moue osteoblast. African J Pharmac Pharmacol. 2010;4:453-464

62 Uemura S, Matsushita H, Li W, et al. Diabetes mellitus enhances vascular matrix metalloproteinase activity: role of oxidative stress. Circ Res 2001;88(12):1291-1298

63 Hoffmann S, Friedrichs U, Eichler W, Rosenthal A, Wiedemann P. Advanced glycation end products induce choroidal endothelial cell proliferation, matrix metalloproteinase- 2 and VEGF upregulation in vitro. Graefes Arch Clin Exp Ophthalmol 2002;240(12):996-1002

64 Zhu P, Ren M, Yang C, Hu YX, Ran JM, Yan L. Involvement of RAGE, MAPK and NF- $\mathrm{KB}$ pathways in AGEs-induced MMP-9 activation in HaCaT keratinocytes. Exp Dermatol 2012;21(2):123-129

65 Zhang F, Banker G, Liu X, et al. The novel function of advanced glycation end products in regulation of MMP-9 production. J Surg Res 2011;171(2):871-876

66 Song W, Ergul A. Type-2 diabetes-induced changes in vascular extracellular matrix gene expression: relation to vessel size. Cardiovasc Diabetol 2006;5:3

67 Rajagopalan S, Meng XP, Ramasamy S, Harrison DG, Galis ZS. Reactive oxygen species produced by macrophage-derived foam cells regulate the activity of vascular matrix metalloproteinases in vitro. Implications for atherosclerotic plaque stability. J Clin Invest 1996;98(11):2572-2579

68 Siwik DA, Pagano PJ, Colucci WS. Oxidative stress regulates collagen synthesis and matrix metalloproteinase activity in cardiac fibroblasts. Am J Physiol Cell Physiol 2001;280(1):C53-C60

69 Koyama H, Yamamoto H, Nishizawa Y. Endogenous secretory RAGE as a novel biomarker for metabolic syndrome and cardiovascular diseases. Biomark Insights 2007:2:331-339 